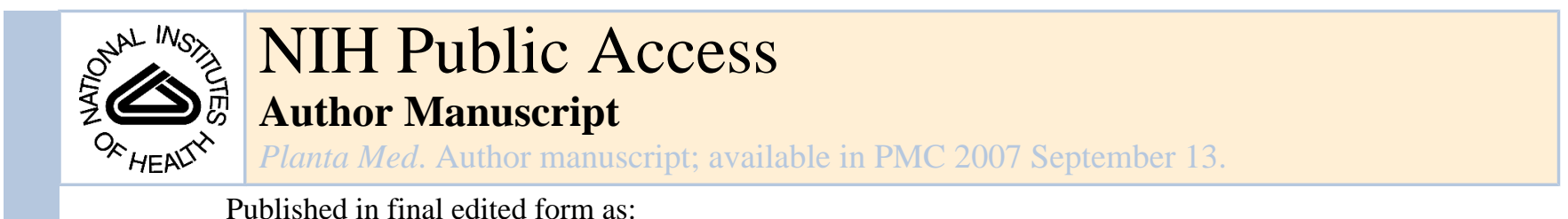

Published in final edited form as:

Planta Med. 2006 October ; 72(13): 1207-1215.

\title{
Year-and-a-Half Old, Dried Echinacea Roots Retain Cytokine- Modulating Capabilities in an in vitro Human Older Adult Model of Influenza Vaccination
}

\author{
David S. Senchina ${ }^{1,2}$, Lankun $\mathrm{Wu}^{3}$, Gina N. Flinn ${ }^{4}$, Del N. Konopka ${ }^{2}$, Joe-Ann McCoy ${ }^{5}$, Mark \\ P. Widrelechner ${ }^{5}$, Eve Syrkin Wurtele ${ }^{3}$, and Marian L. Kohut ${ }^{1,2,6}$ \\ 1 Immunobiology Program, Iowa State University, Ames, Iowa, USA \\ 2 Department of Health and Human Performance, Iowa State University, Ames, Iowa, USA \\ 3 Department of Ecology, Evolution, and Organismal Biology, Iowa State University, Ames, Iowa, USA \\ 4 Department of Genetics, Iowa State University, Ames, Iowa, USA \\ 5 North Central Regional Plant Introduction Station, United States Department of Agriculture, Ames, Iowa, \\ USA \\ 6 Gerontology Program, Iowa State University, Ames, Iowa, USA
}

\begin{abstract}
Alcohol tinctures prepared from aged Echinacea roots are typically taken for preventing or treating upper respiratory infections, as they are purported to stimulate immunity in this context. The effects of long-term (> 1 year) dry storage on the capabilities of Echinacea spp. roots from mature individuals to modulate cytokine production are unknown. Using an older human adult model of influenza vaccination, we collected peripheral blood mononuclear cells from subjects 6 months postvaccination and stimulated them in vitro with the two Type A influenza viruses contained in the trivalent 2004-2005 vaccine with a 50\% alcohol tincture prepared from the roots of one of seven Echinacea species: E. angustifolia, E. pallida, E. paradoxa, E. purpurea, E. sanguinea, E. simulata, and $E$. tennesseensis. Before being processed into extracts, all roots had been stored under dry conditions for sixteen months. Cells were cultured for 48 hours; following incubation, supernatants were collected and assayed for interleukin-2, interleukin-10, and interferon- $\gamma$ production, cytokines important in the immune response to viral infection. Four species $(E$. angustifolia, E. purpurea, E. simulata, E. tennesseensis) augmented IL-10 production, diminished IL-2 production, and had no effect on IFN- $\gamma$ production. Echinacea pallida suppressed production of all cytokines; E. paradoxa and E. sanguinea behaved similarly, although to a lesser extent. The results from these in vitro bioactivity assays indicate that dried Echinacea roots stored for sixteen months maintain cytokine-modulating capacities. Our data support and extend previous research and indicate that tinctures from different Echinacea species have different patterns of immune modulation; further, they indicate that certain species may be efficacious in the immune response to viral infection.
\end{abstract}

Correspondence Marian L. Kohut, 246 Forker Building, Department of Health \& Human Performance, Iowa State University, Ames, Iowa 50011-1160, USA, Phone: +1-515-294-8364, Fax: +1-515-294-8740, E-mail: mkohut@iastate.edu

Supporting information available online at http://www.thieme-connect.de/ejournals/toc/plantamedica 


\section{Keywords}

Echinacea angustifolia; Echinacea pallida; Echinacea paradoxa; Echinacea purpurea; Echinacea sanguinea; Echinacea simulata; Echinacea tennesseensis; interleukin-2; interleukin-10; interferongamma; influenza; tincture

\section{Introduction}

The use of Echinacea phytomedicinal preparations has grown in the past few decades [1], [2]. Echinacea has documented immunomodulatory properties and is most frequently consumed to prevent or minimize symptoms from upper respiratory infections, although scientific studies regarding its efficacy in this capacity report dissimilar findings [3]. Echinacea can alter patterns of cytokine production in vitro as shown previously [4], [5], and this may increase resistance to infection. Some cytokines important in response to viral infection include interleukin-2 (IL-2; enhances T-helper cell function, important in adaptive immunity against many viruses), IL-10 (regulator of cytokine synthesis with anti-inflammatory actions), and interferon- $\gamma$ (IFN$\gamma$, an antiviral cytokine). Although a well-controlled clinical trial recently demonstrated that Echinacea angustifolia did not minimize viral load in response to rhinovirus challenge [6], it is possible that various Echinacea species may alter cytokine expression in such a way as to reduce inflammation and associated symptoms.

Recently, progress has been made to better understand the effects of drying on bioactive constituents of Echinacea roots. Both commercial manufacturers and lay herbalists commonly employ drying processes. The effects of commercial drying regimens (i.e., high temperatures and short drying times, sometimes involving techniques such as convection drying, freeze drying, or vacuum drying) on bioactive constituents of Echinacea have been studied [7], [8], [9], [10], [11], [12], [13]; however, various teams report conflicting findings. It is even less clear how drying conditions such as those a lay herbalist would employ may affect bioactivity of Echinacea roots; however, Perry et al. [14] have reported that alkamide levels dropped 80 $\%$ when E. purpurea roots were stored at $24{ }^{\circ} \mathrm{C}$ for 64 weeks, a method similar to that employed by lay herbalists. Data on the effects of longer-term storage (> 1 year) are lacking. Medicinal plants may be capable of retaining their medicinal properties long after harvest, as has been recently demonstrated with an 85-year-old specimen of black cohosh (Actaea racemosa L.) [15].

The effects of plant age on root bioactive constituent concentrations have also been investigated. However, the results of these studies are conflicting. The roots from older plants may have increased, decreased, or similar levels of constituents compared to younger counterparts per the specific constituent [16], [17].

While numerous phytomedicinal studies of Echinacea spp. roots have been reported, only a handful of these reports state specifically that dried roots were employed. In vitro cytokine production from mouse splenocyte cultures stimulated with water and ethanol/water extracts of dried E. purpurea roots and leaves has been investigated. Various extracts increased production of IL-6, IL-10, MIP-1 $\alpha$, and TNF- $\alpha$, but not IL-2, IL-12, or IFN- $\gamma$ [4]. In other studies, E. purpurea dried root powder has shown cyclooxygenase-inhibiting properties in both in vitro [18] and ex vivo [19] models. Granulocytes from mice fed Echinacea (several spp.) demonstrated higher levels of stimulation both during and immediately after the feeding period as compared to granulocytes from control mice [20]. Splenic lymphocytes from mice treated with E. purpurea dried root powder showed greater apoptosis resistance compared to nontreated controls, suggested by down-regulation of Fas-Ag expression and up-regulating Bcl-2 expression at the cell surface [21]. In combination with roots of wild indigo (Baptisia 
tinctoria L. [Vent], Fabaceae) and shoots of white cedar (Thuja occidentalis L, Cupressaceae), extracts of dried E. pallida and E. purpurea roots lowered mortality, increased mean survival time, reduced lung consolidation, and reduced lung viral titer in mice infected with influenza Type A [22].

Despite these data, it is difficult to compare the results from different researchers because several important variables were not reported, including: (a) age of plant at time of harvest; (b) length of drying time; (c) drying and storage conditions; (d) accession and origin of plant materials used; and (e) plant handling conditions (i.e., was the plant kept intact, portioned, chopped, etc.?).

The aim of the present study was to investigate the effects of sixteen months of dry storage on the immunomodulatory properties of roots from defined accessions of seven Echinacea species by using an older human adult model of influenza vaccination. Our hypothesis was that Echinacea roots stored under dry conditions for sixteen months and then processed into alcohol tinctures would retain cytokine-modulating capabilities, although these effects would vary by species. To test this hypothesis, we isolated peripheral blood mononuclear cells from older humans (> 64 years of age) who had been vaccinated with the trivalent influenza vaccine 6 months prior to this study. Cells were incubated in vitro for 48 hours with Echinacea tinctures or control, along with influenza antigen. We tested supernatants for the synthesis of IL-2, IL-10, and IFN- $\gamma$, cytokines known to be important in the immune response to upper respiratory infections such as influenza [23].

\section{Materials and Methods}

\section{Plant collection, drying, and storage}

All plant material used in this study was harvested in December 2003 from the North Central Regional Plant Introduction Station in Ames, Iowa. Every attempt was made to keep root bundles intact upon excavation; further, all aerial parts were left attached. The following species were collected and are given with their respective accession identifiers as well as the abbreviations by which they and the corresponding tinctures will be referred to in this publication: E. angustifolia var. strigosa (ANG; PI631302A), E. pallida (PAL; PI631275), E. paradoxa var. neglecta (PAR; PI631263), E. purpurea (PUR; unknown parentage), E. sanguinea (SAN; PI631257C), E. simulata (SIM; PI631304A), and E. tennesseensis (TEN; PI631250C). Voucher specimens for PUR, SAN, and TEN were deposited at Ada Hayden Herbarium, Ames, IA (ISC 435975,434027, and 435980, respectively). Vouchers for ANG, PAL, and SIM were prepared by K. McKeown (McKeown \#97004,97007,97002, respectively). All collections are available through the Station; images and respective data may be found at http://www.ars-grin.gov/npgs.

Whole plants were taken to the laboratory for temporary storage before being moved to a climate-controlled facility for sixteen months of storage. This room was held at $25.5-26.5^{\circ}$ $\mathrm{C}$ and $38 \%$ relative humidity during the study as determined by a separate temperature hygrometer. Plants were hung upside down during this time. No special plant preparatory or drying procedures were used.

\section{Extract preparation}

Following storage, plants were removed to the laboratory where ethanol tinctures consisting of 50\% ethanol and 50\% sterile water were prepared from roots. In all cases, plant crosssections and/or shavings were produced using a surgical scalpel and combined with solvent as 1 part plant, 9 parts solvent. Preparations were steeped at room temperature for 20 minutes on 
a horizontal agitator before being filtered through sterilized tulle and stored at $-20{ }^{\circ} \mathrm{C}$ until use.

\section{High-performance liquid chromatography}

Phytochemical analysis was performed to detect alkamides and caffeic acid derivatives in the Echinacea extracts with the use of high-performance liquid chromatography (HPLC). Before analysis, into $160 \mu \mathrm{L}$ of Echinacea extracts, $15 \mu \mathrm{L}\left(1 \mathrm{mg} \mathrm{mL}^{-1}\right) N$-isobutylundeca-2-ene-8,10diynamide $\left(\mathrm{C}_{15} \mathrm{H}_{21} \mathrm{O}_{2}\right)$ and $15 \mu \mathrm{L}\left(1 \mathrm{mg} \mathrm{m} \mathrm{L}^{-1}\right)$ 3,5-dimethoxy-4-hydroxycinnamic acid $\left(\mathrm{C}_{11} \mathrm{H}_{12} \mathrm{O}_{5}\right)$ were added as internal standards for quantification of lipophilic metabolites and hydrophilic metabolites, respectively. Fifteen microliters of each sample were injected into a Beckman Coulter HPLC with a 508 autosampler, 126 pump control and 168 UV-photodiode array detector controlled by $32 \mathrm{karat}^{\mathrm{TM}}$ software (Version 5.0), and a YMC-Pack ODS-AM RP C18 $(250 \times 4.6 \mathrm{~mm}, 5 \mu \mathrm{m})$ analytical column (Waters; Bedford, MA, USA). The solvent system for lipophilic constituents was acetonitrile/ $\mathrm{H}_{2} \mathrm{O}$ at a flow rate of $1.0 \mathrm{~mL} / \mathrm{min}$ following a linear gradient of 40-80\% acetonitrile over $45 \mathrm{~min}$. The solvent system for hydrophilic constituents consisted of acetonitrile/ $\mathrm{H}_{2} \mathrm{O}$ and $0.01 \%$ formic acid, at a flow rate of $1.0 \mathrm{~mL} / \mathrm{min}$ following a linear gradient of 10-35\% acetonitrile over $25 \mathrm{~min}$. Online UV spectra were collected between 190 and $400 \mathrm{~nm}$.

For compound identification, alkamides 8/9, cichoric acid, echinacoside, caftaric acid and cynarin were purchased from Phytolab (Vestenbergsgreuth, Germany); chlorogenic acid was purchased from Sigma Aldrich (St. Louis, MO, USA); alkamides 8, 10, 11, 12, 13, and 14 and ketone 22 were synthesized by Dr. George Kraus, Department of Chemistry, Iowa State University [24], [25]. In the absence of standards, alkamides $\mathbf{1 , ~ 2 , ~ 3 , ~ 4 , ~ 5 , ~} 7$ and ketone 24 were identified by HPLC fractionation coupled with GC-MS analysis. Phytochemicals were quantified based on the internal standard with the limit of HPLC detection at approximately $0.02 \mu \mathrm{g} / \mathrm{mL}$

\section{Human subjects and PBMC isolation}

All procedures involving human subjects were approved by the Institutional Review Board (ethics commission) at Iowa State University and Des Moines University of Osteopathic Medicine. Forty subjects were recruited. Exclusion/inclusion criteria were dependent on age, health status, and medication and supplement use. The minimal age of subjects was 64 . Subjects reporting cancer within the last 5 years, or autoimmune disorders or other disorders likely to impact on immune variables, were excluded. Individuals treated with medications that might significantly alter immune variables (i.e., oral corticosteroids) or medications for treating anxiety/depression were excluded. In addition, subjects taking dietary supplements thought to alter immune responses were excluded. In October 2004, participants received the trivalent influenza vaccine containing A/New Caledonia/20/99 (H1N1), A/Wyoming/03/2003 (H3N2), and B/Jiangsu/10/2003 (Aventis Pasteur; Swiftwater, PA, USA). Six months post-vaccination (April 2005), subjects returned to the laboratory for a blood draw to be used for testing the Echinacea extracts. Peripheral blood mononuclear cells (PBMC) were isolated using FicollPaque plus (Amersham Pharmacopia Biotech; Piscataway, NJ, UAS) gradient centrifugation, counted manually using a hemacytometer, and adjusted to a concentration of $1.0 \times 10^{6}$ cells/ $\mathrm{mL}$ in AIM-V media (GIBCO/Invitrogen; Carlsbad, CA, USA).

\section{Vaccine efficacy}

To determine whether the vaccine elicited an immunological response in subjects, hemagluttination inhibition (HI) assays as described elsewhere by Kohut et al. [26] were performed. Sera were collected pre- and four weeks post-vaccination, and HI titer (antibody response) was measured for the Influenza A/New Caledonia/20/99 (H1N1) and Influenza A/ Wyoming/03/2003 (H3N2) viruses contained in the vaccine. 


\section{Influenza-specific activation of PBMCs}

$1.0 \times 10^{6}$ cells were plated per well in 24-well Costar plates. Each well received either $50 \mu \mathrm{L}$ of one of the Echinacea preparations diluted 1:12.5 or a solvent vehicle control containing an equal volume of ethanol as the extract. The ethanol for the solvent vehicle control was diluted in AIM-V media. This extract concentration was selected based on preliminary studies of cell ethanol tolerance (data not shown). Wells received $10 \mathrm{HA}$ units $/ \mathrm{mL}$ of either the Influenza A/ New Caledonia/20/99 (H1M1) virus or the Influenza A/Wyoming/03/2003 (H3N2) virus identical to that contained in the vaccine to stimulate virus-specific cytokine production. Based on several previous studies, the wells that do not contain virus typically have cytokine levels ranging from undetectable up to $10-30 \mathrm{pg} / \mathrm{mL}$ at peak time points of in vitro culture. The cytokine levels in wells containing virus are typically 10- to 100-fold greater than the cytokine level in wells containing media or vehicle alone, suggesting that the response detected is antigen-specific. The Echinacea preparations were added to culture wells at the same time that virus was added. Control wells received virus identical to Echinacea-treated wells, but received the solvent vehicle control instead of an Echinacea preparation.

\section{Cytokine assays}

Cells were incubated for 48 hours at $37^{\circ} \mathrm{C}, 5.0 \%$ carbon dioxide in humidified conditions for the cytokine assay. Following incubation, the supernatants were harvested and stored at $-20^{\circ}$ $\mathrm{C}$ until used in cytokine quantification assays. Cytokines [interleukin-2 (IL-2), IL-10, and interferon- $\gamma($ IFN- $\gamma$ )] were quantified by ELISA (BD Biosciences Pharmingen; San Diego, CA, USA).

\section{Endotoxin determination}

Measures were taken to minimize endotoxin contamination. All glassware was baked at $180^{\circ}$ $\mathrm{C}$ for 24 hours prior to use. Sterile water was obtained from the manufacturer labeled for human medical use. Endotoxin levels were determined from both the sterile water ( 0 endotoxin units $[\mathrm{EU}] / \mathrm{mL}$ ) and from all final extracts by using Bio-Whitaker QCL 1000 kits (Cambridge, MA, USA). Levels (in EU/mL) from the extract stocks were as follows: ANG 8.925, PAL 8.553, PAR 9.817, PUR 8.999, SAN 9.222, SIM 8.255, TEN 9.743.

To experimentally determine whether the endotoxin levels seen in the extracts influenced our immune outcomes, we isolated PBMC from four healthy, young adults according to the methods described above. Cells were cultured for 24 hours in AIM-V media with $50 \mu \mathrm{L}$ of stock concentrations of Escherichia coli endotoxin at $10 \mathrm{EU} / \mathrm{mL}$ or $100 \mathrm{EU} / \mathrm{mL}$ or sterile water $(0 \mathrm{EU} / \mathrm{mL})$. The $10 \mathrm{EU} / \mathrm{mL}$ stock represented an endotoxin level $>12.5 \times$ higher than our Echinacea diluted extract with the highest endotoxin level (PAR), and the $100 \mathrm{EU} / \mathrm{mL}$ stock represented an endotoxin level known to be immunostimulatory. For the endotoxin assay, supernatants were collected and cytokines [IL-2, IL-10, interleukin-1 $\beta$ (IL-1 $\beta$ ), and tumor necrosis factor- $\alpha$ (TNF- $\alpha)$ ] quantified by ELISA (BD Biosciences Pharmingen).

\section{Statistical analyses}

A two-way ANOVA [species $\times$ virus type] was used to compare differences in cytokine production by using SPSS (Chicago, IL, USA) software. One-way ANOVA was used to determine the effects of different endotoxin doses on cytokine production. Statistical significance was defined as $\alpha=0.05$.

\section{Results}

Extracts prepared by using methods resembling those of lay herbalists may harbor endotoxin from contaminating bacterial populations growing on the plant, and endotoxin is a known 
mitogen in vitro. To determine experimentally if endotoxin levels in our extracts may be influencing immune outcomes, we tested stock concentrations of $E$. coli endotoxin against human PBMC. Results are shown in Fig. 1. Cytokine production from cells receiving the diluted stock of $10 \mathrm{EU} / \mathrm{mL}$ was not significantly different from control $(0 \mathrm{EU} / \mathrm{mL})$ for $\mathrm{IL}-1 \beta$ $(\mathrm{p}=0.995), \mathrm{IL}-10(\mathrm{p}=0.973)$, and TNF- $\alpha(\mathrm{p}=0.98)$; however, cells receiving the diluted stock of $100 \mathrm{EU} / \mathrm{mL}$ produced higher levels of cytokine as compared to control for IL- $1 \beta(\mathrm{p}=0.068)$, IL-10 ( $p=0.044)$, and TNF- $\alpha(p=0.005)$. No differences were observed for IL-2, which is expected, as this is primarily a T-cell-produced cytokine with little responsiveness to endotoxin [27].

The phytochemical analysis of our extracts for alkamides, ketones, and caffeic acid derivatives is presented in Table 1 and Fig. 1S in the Supporting Information. Extracts from ANG, PUR, and SAN had the highest concentrations of alkamides. PAL, PAR, and SIM had the highest concentrations of ketones. Contents of caffeic acid derivatives differed by specific molecule. Overall, PUR had the highest total concentration of caffeic acid derivatives, and PAL had the greatest diversity of molecules.

Hemagluttination inhibition assays for vaccine efficacy indicated that subjects responded to the vaccination. Antibody titers for Influenza A/Wyoming/03/2003 (H3N2) were $6.9 \pm 1.5$ prevaccination compared to $8.0 \pm 1.8$ post-vaccination $(p<0.001)$. Antibody titers for Influenza A/New Caledonia/20/99 (H1N1) increased, but were not significantly different ( $6.38 \pm 1.0$ prevaccination, $6.43 \pm 1.2$ post-vaccination), likely due to the presence of this same H1N1 antigen in several previous years' influenza vaccines, as other researchers have also shown in this age group [28].

Results for interleukin-10 production are given in Fig. 2. A significant main effect of plant species was observed $(\mathrm{p}<0.001)$ as well as a plant species by virus interaction $(\mathrm{p}=0.038)$. Follow-up analyses were conducted separating results from the two viruses. For Influenza A/ New Caledonia/20/99 (H1N1) alone, a significant effect of plant species remained ( $p=0.001$ ). Four extracts stimulated significant increases in cell production of IL-10 compared to the control condition containing no Echinacea (Fig. 2A): ANG (p < 0.001), PUR (p < 0.001), SIM $(\mathrm{p}=0.001)$, and TEN $(\mathrm{p}=0.002)$. PAL significantly decreased IL-10 production (Fig. $2 \mathrm{~A} ; \mathrm{p}$ $=0.005)$. A similar pattern of results was found for the H3N2 virus. For Influenza A/Wyoming/ 03/2003 (H3N2) alone, a significant effect of plant species remained ( $<<0.001)$.

Extracts from the same four species stimulated increases in IL-10 production (Fig. 2B): ANG $(p<0.001)$, PUR $(p=0.002)$, SIM $(p=0.001)$, and TEN $(p=0.010)$. PAL again significantly decreased IL-10 production ( $\mathrm{p}<0.001)$.

Results for interleukin-2 production are shown in Fig. 3. A significant main effect of plant species was found $(\mathrm{p}<0.001)$. All seven extracts induced statistically significant (all $\mathrm{p}<0.001$ ) reductions in IL-2 production compared to control condition containing no Echinacea.

Results for interferon- $\gamma$ production are displayed in Fig. 4. A significant main effect of plant species was observed $(\mathrm{p}<0.001)$. No extracts significantly augmented IFN $-\gamma$ production. However, three extracts significantly diminished IFN $-\gamma$ synthesis: PAL $(\mathrm{p}<0.001)$, PAR $(\mathrm{p}<$ $0.001)$, and SAN $(\mathrm{p}=0.003)$.

\section{Discussion}

In this study, we employed an in vitro human older adult model of influenza vaccination to assess the bioactivity of Echinacea roots stored dry for sixteen months, specifically focusing on their ability to modulate patterns of cytokine expression in response to antigen challenge. This model had several virtues that made it readily amenable to the questions being addressed 
in this investigation. Echinacea extracts are typically taken for the prevention or treatment of upper respiratory infections, such as influenza [29]. The model chosen here allowed us to test the potential efficacy of Echinacea extracts in an in vitro context of viral infection using human PBMC. The elderly are one segment of the population that typically consumes Echinacea preparations in an attempt to "boost" their immunity [30]. Influenza vaccine efficacy rates in geriatric populations are typically poorer than those of young adult controls, and influenza infection is a major cause of morbidity and mortality in this group [31]. Thus, results from this study may provide information on the potential feasibility of using Echinacea preparations to improve influenza vaccine efficacy rates in older adults. In addition, a better understanding of how Echinacea may modulate cytokines in response to influenza virus challenge in vitro may be a first step in understanding the potential role of Echinacea during an influenza infection in vivo.

The effects of endotoxin in our extracts were explored experimentally (Fig. 1). Cells stimulated with endotoxin levels somewhat higher than levels in the extracts behaved no differently than controls that contained no endotoxin. These findings suggest that endotoxin levels in our Echinacea extracts did not influence the immune outcomes reported here.

Results for our cytokine assays (Figs. 2-4) are summarized in Table 2. As is clear from these figures, even after sixteen months of dry storage, Echinacea roots maintained cytokinemodulating capabilities.

We saw contrasting effects of preparations made from different Echinacea species on the production of interleukins. In general, Echinacea preparations tended to have no effect or increased production of IL-10 (Fig. 2; Table 2). In contrast, all tinctures decreased production of IL-2 (Fig. 3; Table 2). Table 1 does not suggest any single molecule or class of molecules that may be responsible for the IL-10 activities seen in Table 2. According to Table 1, amides and caffeic acid derivatives (but not ketones) were present in all species to varying extents. Chlorogenic acid was the only molecule detectable in extracts from all seven species. It is possible that multiple alkamides or multiple caffeic acid derivatives may be responsible for this activity. One possible explanation for these results is that compounds in Echinacea may promote a down-regulation of the immune response following viral infection (e.g., by producing more IL-10 and less IL-2). This explanation may also support those studies finding a beneficial effect of Echinacea during viral infection [32].

With respect to our findings, Echinacea did not appear to enhance IFN- $\gamma$ (Fig. 4; Table 2). Some species inhibited IFN- $\gamma$, suggesting that these species may not be efficacious in stimulating antibody production if consumed at the time of vaccination. No single molecule or group of molecules from Table 1 was unique to these three species, making it unclear which constituent s) are responsible for these activities. Our results suggest that Echinacea preparations made in the manner employed here may not have a large effect on the production of IFN- $\gamma$. Though IFN- $\gamma$ response following influenza vaccination is reduced in older adults compared to younger counterparts [33], researchers have shown that increases in IFN- $\gamma$ correlate with increases in antibody titer in vaccinated elderly [34]; similarly, a poor Th1 (IFN$\gamma)$ response to influenza vaccine is correlated with reduced antibody response to the vaccine [35]. Therefore, our findings based on the IFN- $\gamma$ response may suggest that Echinacea administered at the time of immunization is not likely to increase antibody response to the vaccine, but direct evidence regarding this possibility is not available from our study. In older adults, the vaccine does not provide complete protection. In the event of influenza infection, cell-mediated immune responses become important clearing virus infection. Cell-mediated responses may be measured by examining proliferative response of PBMC to appropriate antigen. Studies have shown that the proliferative response of PBMC is correlated with influenza-stimulated production of IL-10 in older adults [23]. IL-10 also appears to be 
necessary for the development of specific antibody subclasses in response to influenza vaccine [36]. Based on our results, it is possible that the Echinacea-associated increase in IL-10 may direct antibody subclass development if Echinacea had been administered at the time of vaccination and/or improve response to infection by promoting proliferation of appropriate cell populations. However, clinical trials will be necessary to determine whether Echinacea may alter vaccine efficacy and/or modulate immune responses to influenza virus infection.

Seven species of Echinacea were employed under the same experimental conditions, allowing us to make comparisons across taxa. The most consistent responses were seen from cells stimulated with PAL: in all cases, PAL induced decreases in cytokine production (Table 2). Extracts from two other species, PAR and SAN, also decreased production of IL-2 and IFN$\gamma$, but not IL-10. ANG, PUR, SIM, and TEN augmented production of IL-10 and diminished production of IL-2; no effects were seen on IFN- $\gamma$. These results imply that not all Echinacea species influence cytokine expression in similar fashions, supporting previous results from our lab [5] as well as others [37], [38], [39]. More specifically, extracts from certain species, such as PAL, PAR, and SAN, tend to show repressive effects regardless of the cytokine being assayed, whereas others, such as ANG, PUR, SIM, and perhaps TEN, stimulate cytokinespecific responses. Intriguingly, the three species employed for commercial preparations are E. angustifolia, E. pallida, and E. purpurea, alone or in various combinations [3], [40]. Our results may indicate that these three species do not have similar effects, and may warrant a reassessment of which species are included in commercial preparations and in what particular combinations.

In conclusion, the results from this study suggest that Echinacea roots stored dry for sixteen months maintain cytokine-modulating capabilities. Additionally, they suggest that different Echinacea species may act on cytokine expression in different fashions. Whether or not Echinacea extracts may have utility as influenza vaccine boosters and/or a beneficial role during actual influenza infection is not addressed directly by this study; however, our in vitro findings do suggest the plausibility of such an application. Finally, more studies are needed to examine relationships between the phytochemical composition of extracts and extract fractions and immunomodulatory activities of these materials to identify possible bioactive molecules and their associated effects.

\section{Supplementary Material}

Refer to Web version on PubMed Central for supplementary material.

\section{Acknowledgements}

This publication was made possible by grant number P01ES012020 from the National Institute of Environmental Health Sciences (NIEHS) and the Office of Dietary Supplements (ODS), NIH. Its contents are solely the responsibility of the authors and do not necessarily represent the official views of the NIEHS, NIH. The investigators wish to thank all the participants for their involvement. Ryan Rapp prepared some of the vouchers. Virus was kindly provided by Brenda Schwarz. Kathleen Mullin and Jolene Muse courteously provided use of a climate-controlled room for plant storage. Zili Zhai and Joan E. Cunnick determined endotoxin levels of extracts and supplied the purified endotoxin used in the experiments. Dustin A. McCann ran the ELISAs on the endotoxin experiment.

\section{References}

1. Barnes PM, Powell-Griner E, McFann K, Nahin RL. Complementary and alternative medicine use among adults: United States, 2002. Adv Data 2004;343:1-19. [PubMed: 15188733]

2. Bent SRK. Commonly used herbal medicines in the United States: a review. Am J Med 2004;116:47885. [PubMed: 15047038]

3. Barrett BP. Medicinal properties of Echinacea: a critical review. Phyto-medicine 2003;10:66-86. 
4. Hwang SA, Dasgupta A, Actor JK. Cytokine production by non-adherent mouse splenocyte cultures to Echinacea extracts. Clin Chim Acta 2004;343:161-6. [PubMed: 15115689]

5. Senchina DS, McCann DA, Asp JM, Johnson JA, Cunnick JE, Kaiser MS, et al. Changes in immunomodulatory properties of Echinacea spp. root infusions and tinctures stored at $4{ }^{\circ} \mathrm{C}$ for four days. Clin Chim Acta 2005;355:67-82. [PubMed: 15820480]

6. Turner RB, Bauer R, Woelkart K, Hulsey TC, Gangemi JD. An evaluation of Echinacea angustifolia in experimental rhinovirus infections. N Engl J Med 2005;353:341-8. [PubMed: 16049208]

7. Kabganian R, Carrier DJ, Sokhansanj S. Drying of Echinacea angustifolia roots. J Herbs Spices Med Plants 2002;10:1 -9.

8. Kabganian R, Carrier DJ, Sokhansanj S. Physical characteristics and drying rate of Echinacea root. Drying Technol 2002;20:637-50.

9. Kim HO, Durance TD, Seaman CH, Kitts DD. Retention of alkamides in dried Echinacea purpurea. J Agric Food Chem 2000;48:4187-92. [PubMed: 10995335]

10. Kim HO, Durance TD, Seaman CH, Kitts DD. Retention of caffeic acid derivatives in dried Echinacea purpurea. J Agric Food Chem 2000;48:4182-6. [PubMed: 10995334]

11. Li TSC, Wardle DA. Effects of root drying temperature and moisture content on the levels of active ingredients in Echinacea roots. J Herbs Spices Med Plants 2001;8:15-21.

12. Stuart DL, Wills RBH. Effect of drying temperature on alkamides and cichoric acid concentrations of Echinacea purpurea. J Agric Food Chem 2003;51:1608-10. [PubMed: 12617592]

13. Wills RBH, Stuart DL. Effect of handling and storage on alkylamides and cichoric acid in Echinacea purpurea. J Sci Food Agric 2000;80:1402-6.

14. Perry NB, van Klink JW, Burgess EJ, Parmenter GA. Alkamide levels in Echinacea purpurea: effects of processing, drying, and storage. Planta Med 2000;66:54-6. [PubMed: 10705735]

15. Jiang B, Yang H, Nuntanakorn P, Balick MJ, Kronenberg F, Kennelly EJ. The value of plant collections in ethnopharmacology: a case study of an 85-year-old black cohosh (Actaea racemosa L.) sample . J Ethnopharmacol 2005;96:521-8. [PubMed: 15619573]

16. Binns SE, Arnason JT, Baum BR. Phytochemical variation within populations of Echinacea angustifolia (Asteraceae). Biochem Syst Ecol 2002;30:837-54.

17. Gray DE, Pallardy SG, Garrett HE, Rottinghaus GE. Acute drought stress and plant age effects on alkamide and phenolic acid content in purple coneflower roots. Planta Med 2003;69:50-5. [PubMed: 12567279]

18. Clifford LJ, Nair MG, Rana J, Dewitt DL. Bioactivity of alkamides isolated from Echinacea purpurea (L. ) Moench Phytomedicine 2002;9:249-53.

19. Raso CM, Pacilio M, Di Carlo G, Esposito E, Pinto L, Meli R. In-vivo and in-vitro anti-inflammatory effect of Echinacea purpurea and Hypericum perforatum. J Pharm Pharmacol 2002;54:1379-83. [PubMed: 12396300]

20. Sestakova, H.; Turek, B. Echinacea: the genus Echinacea. Miller, SC., editor. Boca Raton: CRC Press; 2004.

21. Di Carlo G, Nuzzo I, Capasso R, Sanges MR, Galdiero E, Capasso F, et al. Modulation of apoptosis in mice treated with Echinacea and St. John's wort Pharmacol Res Commun 2003;48:273-7.

22. Bodinet C, Mentel R, Wegner U, Lindequist U, Teuscher E, Freudenstein J. Effect of oral application of an immunomodulating plant extract on influenza virus type A infection in mice. Planta Med 2002;68:896-900. [PubMed: 12391552]

23. Bernstein E, Gardner E, Abrutyn E, Gross P, Murasko D. Cytokine production after influenza vaccination in a healthy elderly population. Vaccine 1998;16:1722-31. [PubMed: 9778748]

24. Kraus GA, Bae J. Synthesis of N-(2-methylpropyl)-2-undecene-8,10-diynamide, a novel constituent of Echinacea angustifolia. Tetrahedron Lett 2003;44:5505-6. [PubMed: 16971964]

25. Wu L, Bae J, Kraus G, Wurtele ES. Diacetylenic isobutylamides of Echinacea: synthesis and natural distribution. Phytochemistry 2004;65:2477-84. [PubMed: 15381412]

26. Kohut ML, Arntson BA, Lee W, Rozeboom K, Yoon KJ, Cunnick JE, et al. Moderate exercise improves antibody response to influenza immunization in older adults. Vaccine 2004;22:2298-306. [PubMed: 15149789] 
27. Smith KA. Interleukin 2. Annu Rev Immunol 1984;2:319-33. [PubMed: 6443342]

28. Saurwein-Teissl M, Steger MM, Gluck R, Cryz S, Grubeck-Loebenstein B. Influenza vaccination in a healthy geriatric population: preferential induction of antibodies specific for the H3N2 influenza strain despite equal T cell responsiveness to all vaccine strains. Vaccine 1998;16:196-200. [PubMed: 9607030]

29. Lindenmuth GF, Lindenmuth EB. The efficacy of Echinacea compound herbal tea preparation on the severity and duration of upper respiratory and flu symptoms: a randomized, double-blind placebocontrolled study. J Altern Complement Med 2000;6:327-34. [PubMed: 10976979]

30. Bruno JJ, Ellis JJ. Herbal use among US elderly: 2002 National Health Interview Survey. Ann Pharmacother 2005;39:643-8. [PubMed: 15741417]

31. Kohut ML, Senchina DS. Reversing age-associated immunosenescence via exercise. Exerc Immunol Rev 2004;10:6-41. [PubMed: 15633584]

32. Goel V, Lovlin R, Chang C, Slama JV, Barton R, Gahler R, et al. A proprietary extract from the echinacea plant (Echinacea purpurea) enhanced systemic immune response during a common cold. Phytother Res 2005;19:689-94. [PubMed: 16177972]

33. Ouyang Q, Cicek G, Westendorp RGJ, Cools HJM, van der Klis RJ, Remarque EJ. Reduced interferon- $\gamma$ production in elderly people following in vitro stimulation with influenza vaccine and endotoxin. Mech Ageing Dev 2000;121:131-7. [PubMed: 11164467]

34. Bernstein E, Kaye D, Abrutyn E, Gross P, Dorfman M, Murasko DM. Immune response to influenza vaccination in a large healthy elderly population. Vaccine 1999;17:82-94. [PubMed: 10078611]

35. Deng Y, Jing Y, Campbell AE, Gravenstein S. Age-related impaired type $1 \mathrm{~T}$ cell responses to influenza: reduced activation ex vivo, decreased expansion in CTL culture in vitro, and blunted response to influenza vaccination in vivo in the elderly. J Immunol 2004;172:3437-46. [PubMed: 15004143]

36. Dobber R, Tielemans M, Nagelkerken L. The in vivo effects of neutralizing antibodies against IFNgamma, IL-4, or IL-10 on the humoral immune response in young and aged mice. Cell Immunol 1995;160:185-92. [PubMed: 7720078]

37. Binns SE, Hudson J, Merali S, Arnason JT. Antiviral activity of characterized extracts from Echinacea spp. (Heliantheae:Asteraceae) against Herpes simplex virus (HSV-1) . Planta Med 2002;68:780-3. [PubMed: 12357386]

38. Pellati F, Benvenuti S, Melegari M, Lasseigne T. Variability in the composition of anti-oxidant compounds in Echinacea species by HPLC. Phytochem Anal 2005;16:77-85. [PubMed: 15881113]

39. Speroni E, Govoni P, Guizzardi S, Renzulli C, Guerra MC. Anti-inflammatory and cicatrizing activity of Echinacea pallida Nutt. root extract. J Ethnopharmacol 2002;79:265-72. [PubMed: 11801391]

40. Barnes J, Anderson LA, Gibbons S, Phillipson JD. Echinacea species (Echinacea angustifolia (DC.) Hell., Echinacea pallida (Nutt.) Nutt, Echinacea purpurea (L. ) Moench): a review of their chemistry, pharmacology and clinical properties. J Pharm Pharmacol 2005;57:929-954. [PubMed: 16102249] 
A

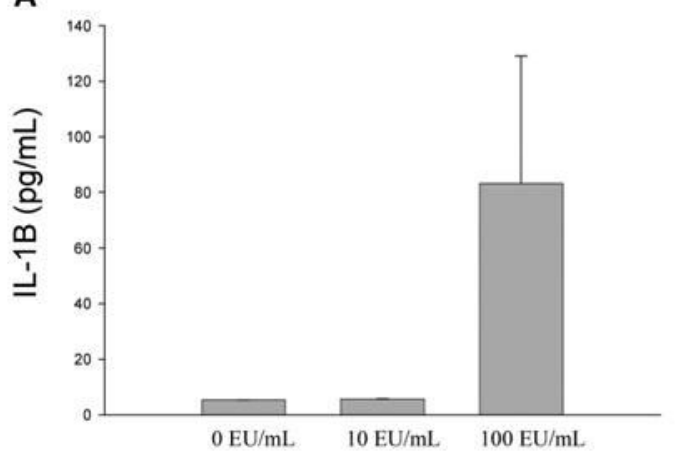

C

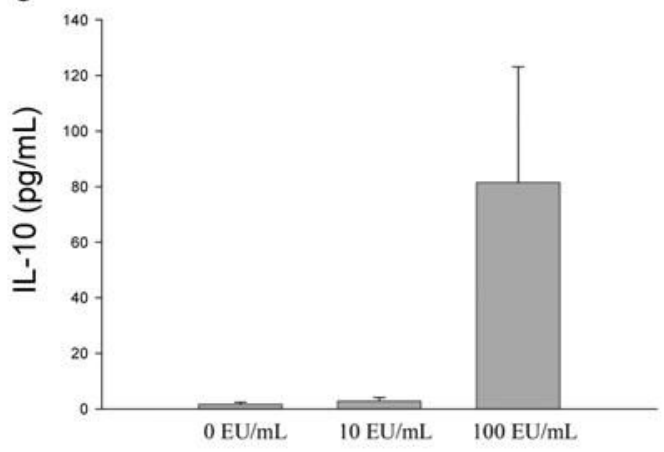

B

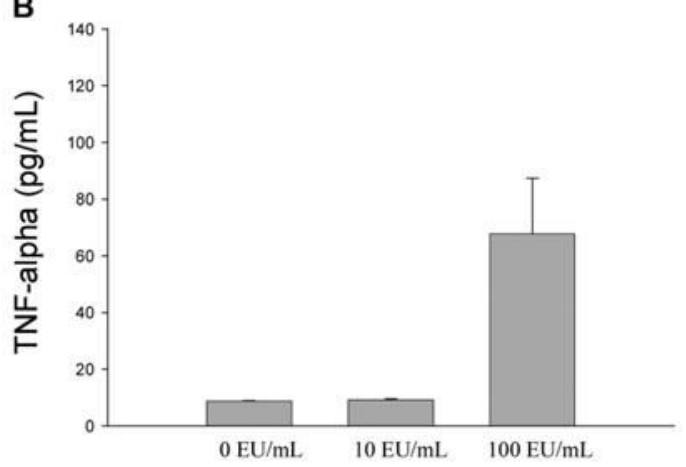

D

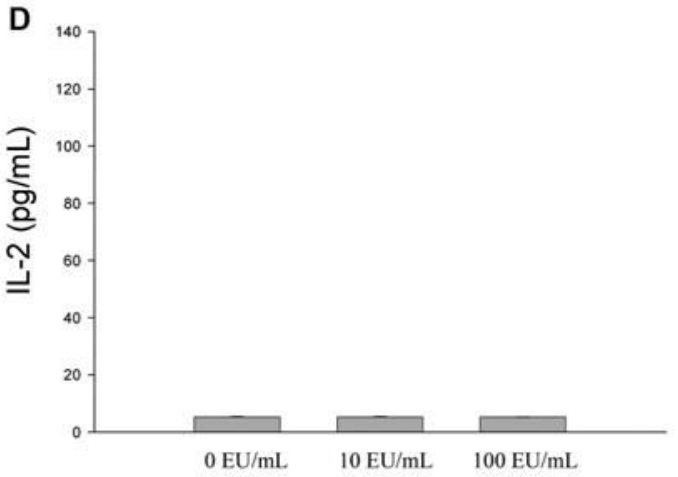

Fig 1.

Cytokine production (in $\mathrm{pg} / \mathrm{mL}$ ) by PBMC stimulated with various levels of endotoxin: (A) IL-1 $\beta$, (B) TNF- $\alpha$, (C) IL-10, (D) IL-2. Bars represent standard errors. 

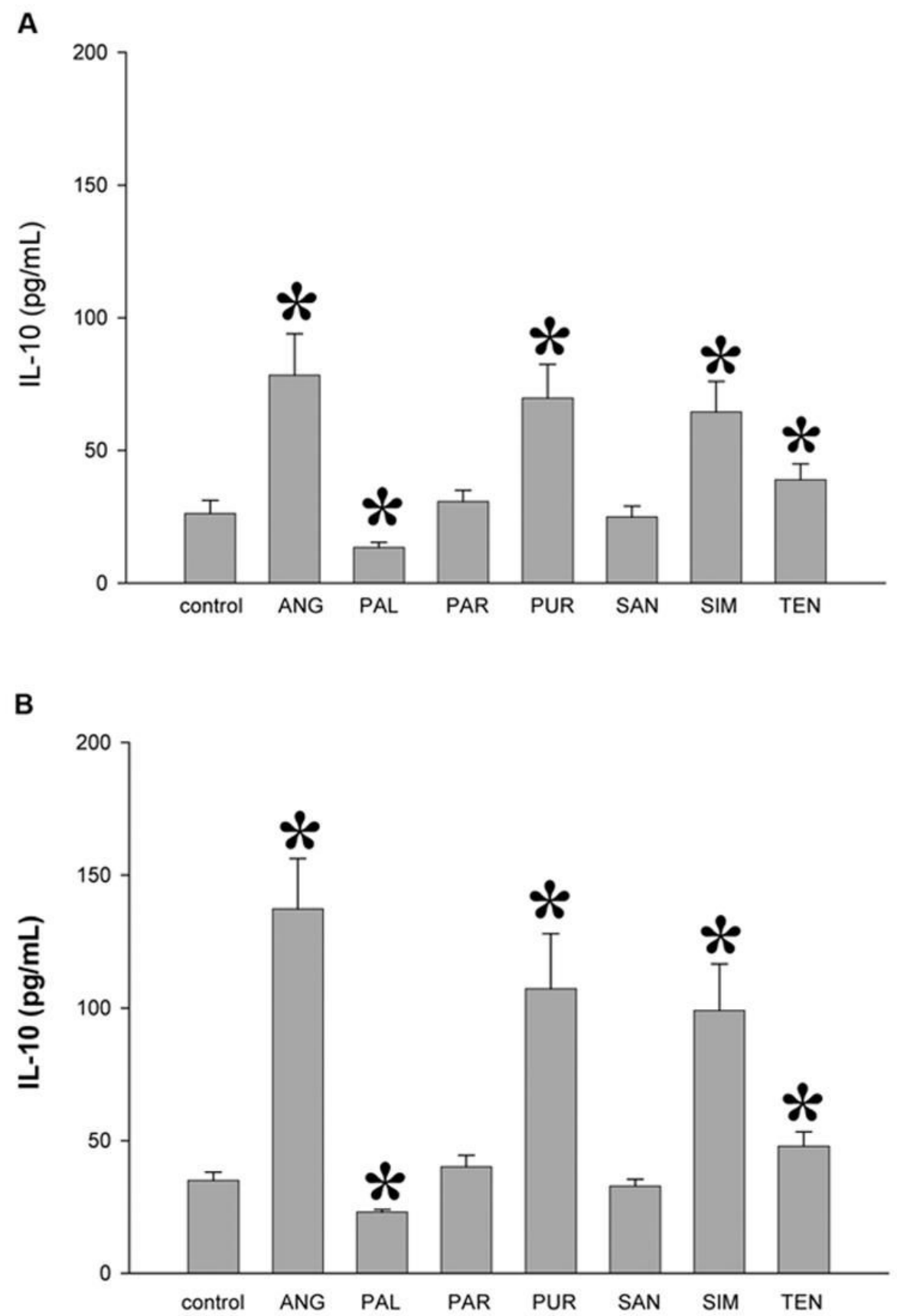

Fig 2.

IL-10 production (in pg/mL) by Echinacea tinctures under H1N1 (A), and H3N2 (B) stimulation. Bars represent standard errors. Note the direction of significance. Species abbreviations: ANC (E. angustifolia var. strigosa), PAL (E. pallida), PAR (E paradoxa var. neglecta), PUR (E purpurea), SAN (E. sanguinea), SIM (E. simulata), and TEN (E. tennesseensis). 
A

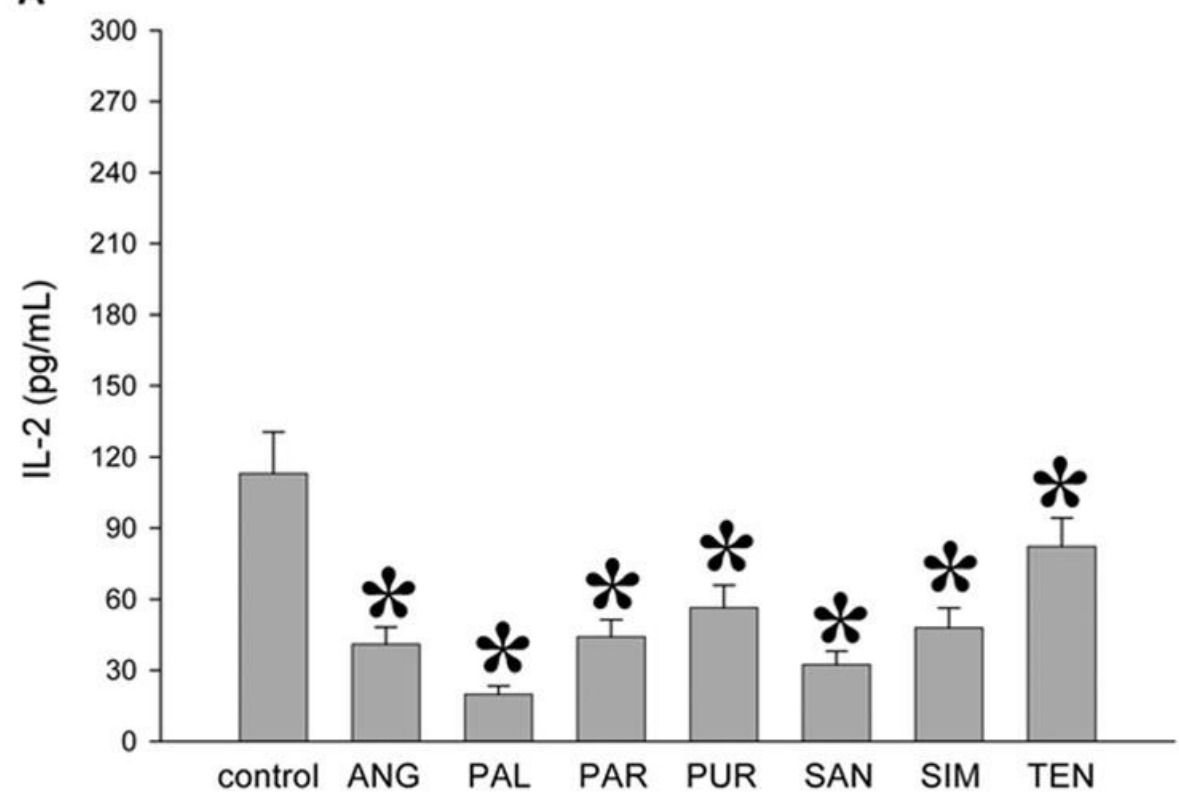

B

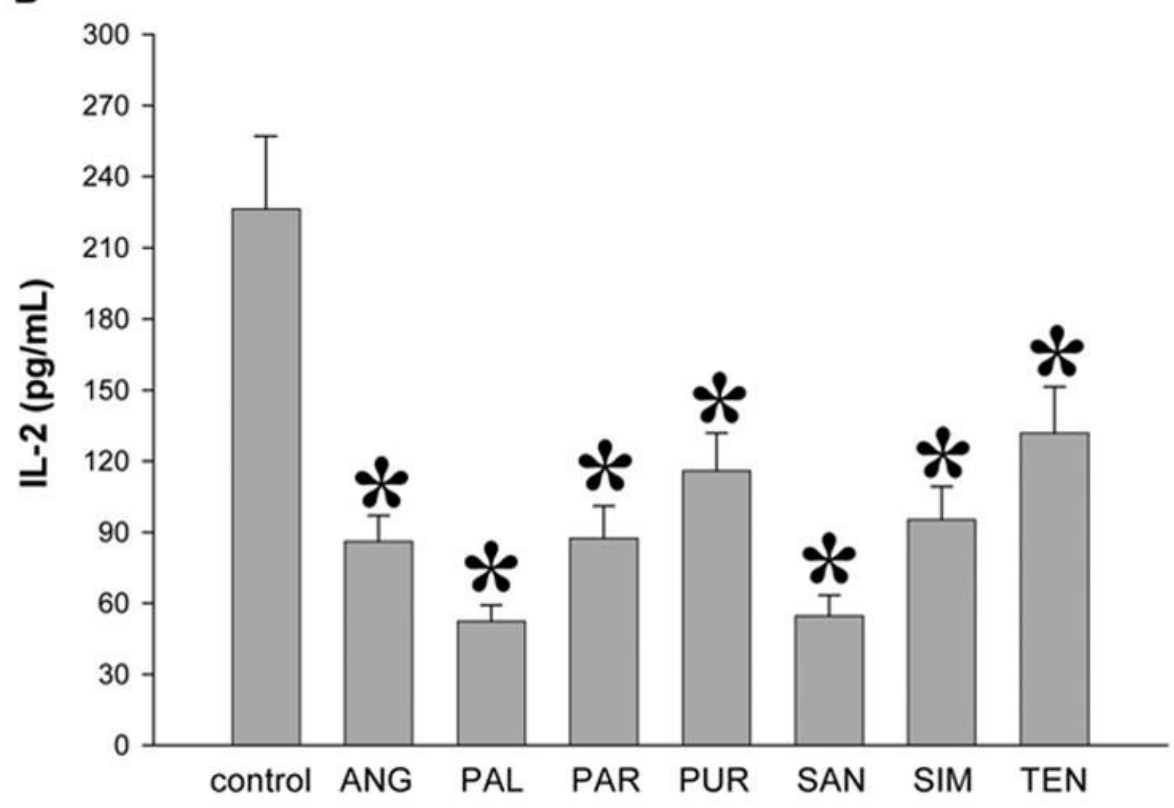

Fig 3.

IL-2 production (in pg/mL) by Echinacea tinctures under HIN1 (A), and H3N2 (B) stimulation. Bars represent standard errors. Species abbreviations: ANG (E. angustifolia var. strigosa), PAL (E. pallida), PAR (E. paradoxa var. neglecta), PUR (E. purpurea), SAN (E. sanguinea), SIM (E simulata), and TEN (E tennesseensis). 

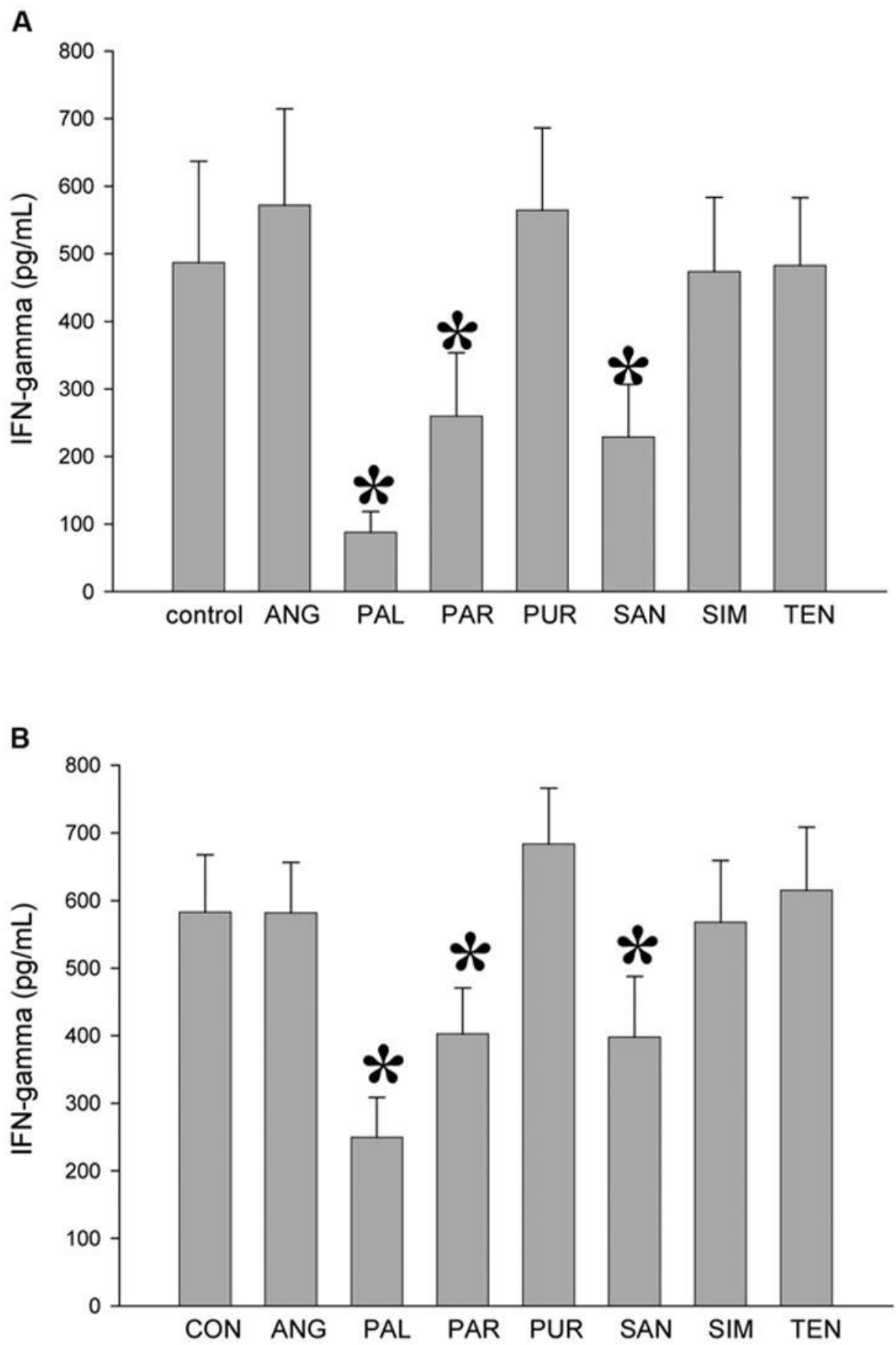

Fig 4.

IFN- $\gamma$ production (in pg/mL) by Echinacea tinctures under H1N1 (A), and H3N2 (B) stimulation. Bars represent standard errors. Species abbreviations: ANC (E. angustifolia var. strigosa), PAL (E. pallida), PAR (E. paradoxa var. neglecta), PUR (E. purpurea), SAN (E. sanguinea), SIM (E simulata), and TEN (E tennesseensis). 
Table 2

Summary of significant effects of Echinacea tinctures on cytokines. Arrows indicate direction of effect

\begin{tabular}{lccc}
\hline & IL-2 & IL-10 & IFN- $\gamma$ \\
\hline ANC & $\downarrow$ & $\uparrow$ & \\
PAL & $\downarrow$ & $\downarrow$ & $\downarrow$ \\
PAR & $\downarrow$ & $\uparrow$ & $\downarrow$ \\
PUR & $\downarrow$ & $\uparrow$ & $\downarrow$ \\
SAN & $\downarrow$ & $\uparrow$ & \\
SIM & $\downarrow$ & $\downarrow$ & \\
\hline
\end{tabular}

Species abbreviations: ANG (E. angustifolia var. strigosa), PAL (E. pallida), PAR (E. paradoxa var. neglecta), PUR (E. purpurea), SAN (E. sanguinea), SIM (E simulata), and TEN (E tennesseensis). 